\title{
REPEAT PASS INTERFEROMETRY USING ALOS-2 PALSAR-2 DATA (STUDY CASE IN BRAZIL)
}

\author{
R. A. S. Rosa ${ }^{1 *}$ C. G. Oliveira ${ }^{1}$, T. G. Rodrigues ${ }^{1}$, E. P. Moreira $^{1}$, V. M. Oliveira ${ }^{1,2}$ \\ ${ }^{1}$ Visiona Tecnologia Espacial S.A., Estrada. Dr. Altino Bondensan, 500, 12247-016, São José dos Campos-SP, Brazil \\ (rafael.rosa, cleber.oliveira, thiago.rodrigues, eder.moreira, vania.oliveira)@ visionaespacial.com.br \\ ${ }^{2}$ National Institute for Space Research - INPE, Av. dos Astronautas, 1758, 12227-010, São José dos Campos-SP, Brazil
}

Commission I, WG I/3

KEY WORDS: SAR, Synthetic Aperture Radar, Interferometry, InSAR, DEM, Digital Elevation Model, PALSAR, ALOS

\begin{abstract}
:
We performed a process called SAR Interferometry (InSAR) to generate Digital Elevation Models (DEMs) from data pairs of the PALSAR-2 Synthetic Aperture Radar, from the ALOS-2 satellite. The pair of images used is a permutation between all acquired acquisitions of SAR data from ALOS-2, more precisely, we used data from two satellite passages (temporally spaced) in which the sensor was imaging the same area on the ground. There were PALSAR-2 L-Band Ultrafine images with an interval of 14 days between acquisitions (which is precisely the revisit time of the satellite) from two forest regions in the Paraná state, Brazil. After the generation of the DEM, we observed a systematic error that generated a kind of very sharp ramp in the azimuthal direction. In this paper we present the followed steps and the investigation carried out to discover the causes of the error. We could observe that the satellite paths on the two dates suffer a relative displacement between them. In other words, this error occurs due to a non-constant baseline. This work was part of the R\&D project of FAPESP (São Paulo State Research Support Foundation) entitled "Geração de inventários florestais a partir de um portfólio de soluções de sensoriamento remoto brasileiras de papel e celulose" (Generation of forest inventories from a portfolio of Brazilian remote sensing solutions for paper and cellulose) number "2017 / 25639 - 5 - NRC PIPE - Fase 2 Direta".
\end{abstract}

\section{INTRODUCTION}

\subsection{SAR Interferometry}

There is a great requirement in many fields of Earth science for accurate knowledge of terrain topography. SAR (Synthetic Aperture Radar) interferometry is a technique that makes a significant contribution to topography mapping. It allows the creation of digital elevation models (DEM) by phase difference between two SAR images which were obtained in slightly different geometric positions, however, highly correlated (Mura et al., 2012).

SAR Interferometry uses a pair of SAR images in a complex format, of amplitude and phase, to generate a third complex image, called an interferofram image, whose phase of each pixel, called interferometric phase, is formed by the phase difference between the pixels corresponding to the two original images. The phase of each pixel of the interferogram image is related to the elevation of the terrain, corresponding to the resolution cell on the ground, thus enabling the generation of a Digital Elevation Model (DEM) (Zhu et al., 2018).

\subsection{Basic Interferometric Equation}

The basic geometry of an SAR interferometric system is illustrated in Figure 1 (Rosa, 2017). The two antennas $A_{1}$ and $A_{2}$ are separated by the baseline $B$, with inclination $\alpha$, at a height $H$ from the ground, with an incidence angle $\theta$. In the case of two-pass interferometry, $A_{1}$ and $A_{2}$ represent the positions of the same antenna, separated from a non-fixed distance $B$. It is noted that by the triangle defined by points $A_{1}, A_{2}$ and $P$, the difference in distance $\Delta r$, is related to the elevation of the point $P$ (Managhebi et al., 2018).

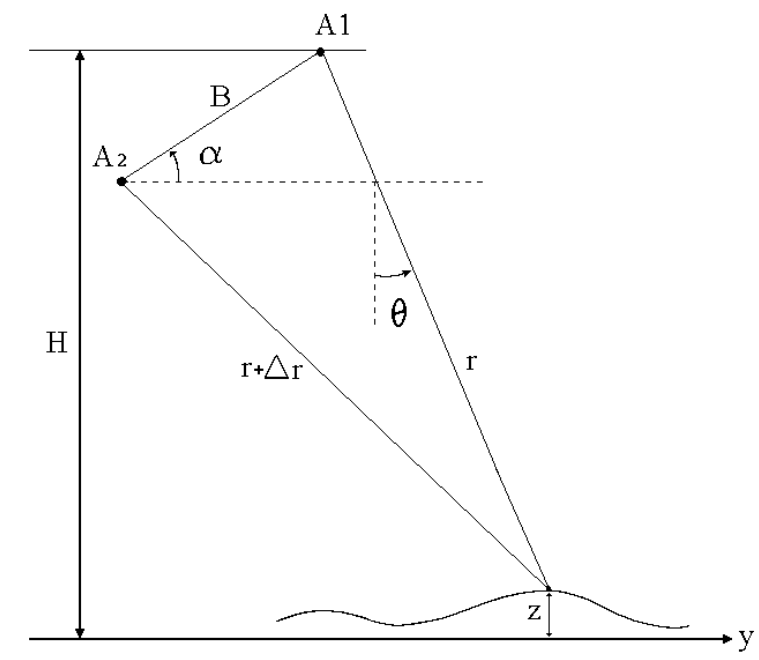

Figure 1. Basic geometry of an interferometric SAR system

The radar signals, transmitted by the antennas $A_{1}$ and $A_{2}$ and received by the respective transmitting antennas, have a phase difference that is proportional to the distance difference $\Delta r$ according to the following equation (Rosa, 2017):

$$
\Delta \phi=\frac{4 \pi \Delta r}{\lambda}
$$


where $\lambda$ is the wavelength of the transmitted signal.

The distance variation $\Delta r$ and, consequently, the phase variation $\Delta \phi$ depend on the baseline length $B$, that is, the distance between $A_{1}$ and $A_{2}$. A very small baseline makes the phase difference signal too small to be detected. If the baseline is very large, the phase becomes noisy due to spatial different acquisition geometries (Yunjun et al., 2019).

SAR interferometry uses the information $\Delta \phi$, obtained through the phase difference between the two images, to generate the $\Delta r$ information and, consequently, obtain the elevation value, as long as the imaging conditions are known, that is, the height $H$, the baseline $B$ and the state vectors (speed and positioning) of the antennas $A_{1}$ and $A_{2}$ (Uemoto et al., 2018).

From the generic triangle comprised of points $A_{1}, A_{2}$ and $P$, we have the following relationship (Rosa, 2017):

$$
(r+\Delta r)^{2}=r^{2}+B^{2}-2 r B \sin (\alpha-\theta)
$$

which can be written as follows:

$$
r=\frac{B^{2}-\Delta r^{2}}{2(\Delta r+B \sin (\alpha-\theta))}
$$

And, with the incidence angle $\theta$ and the distance $r$ from a generic point $P$, we have the following relation to the elevation of this point:

$$
z(r, \theta)=H-r \cos \theta
$$

\section{METHODOLOGY}

We used the software ESA SNAP (Sentinel Application Platform) and we followed the instructions on interferometric processing with Sentinel-1 Stripmap products of the SNAP Interferometry Tutorial to generate a Digital Elevation Model (DEM) (Veci, 2015) from data pairs of the PALSAR-2 Synthetic Aperture Radar, from the ALOS-2 satellite. Figure 2 shows the flowchart of SAR Interferometric Processing.

The pair of images used is a permutation between all acquired acquisitions of SAR data from ALOS-2, more precisely, we used data from two satellite passages (temporally spaced) in which the sensor was imaging the same area on the ground. There were PALSAR-2 L-Band images of Stripmap Ultrafine mode with a spatial resolution of $3.495 \times 3.853 \mathrm{~m}$, from April and May 2019, with an interval of 14 days between acquisitions (which is precisely the revisit time of the satellite) from two forest regions in the Paraná state, Brazil.

We found three works that propose and execute very similar methodologies. However, one of them uses the pair formed by the TerraSAR-X / TanDEM-X satellites, which are two satellites that have the same orbit, one followed by the other with a constant baseline (Ali et al., 2019). The other two works found use data from ALOS-2 / PALSAR-2, but work with the ScanSAR mode, that is, they use data with much lower resolution (from 60 to $100 \mathrm{~m}$ ) which, therefore, are much less sensitive to changes in the baseline (Natsuaki et al., 2016) (Liang, Fielding, 2017). Figure 3 shows the ALOS-2 / PALSAR-2 observation modes and Table 1 has its specifications (JAXA, 2014).

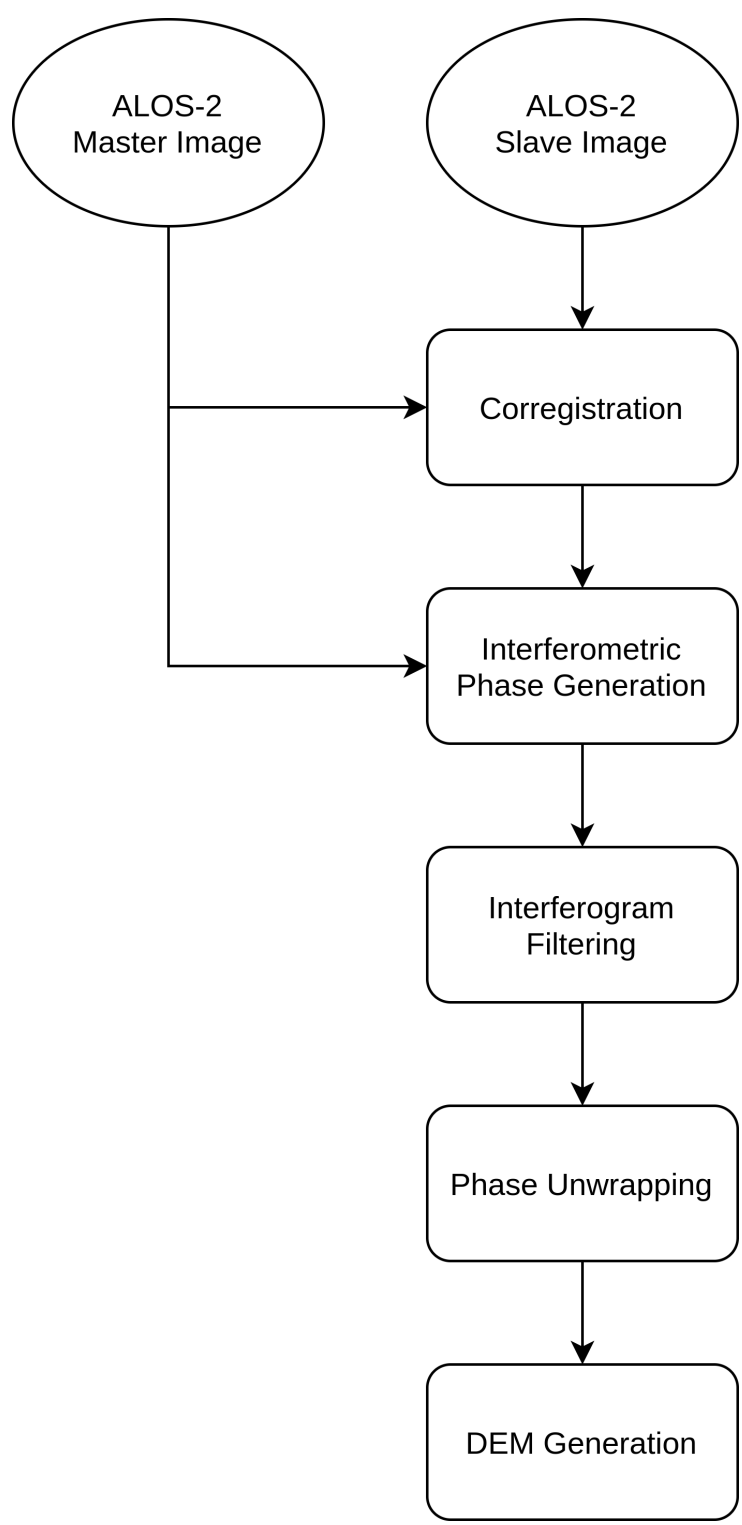

Figure 2. Flowchart of SAR Interferometric Processing

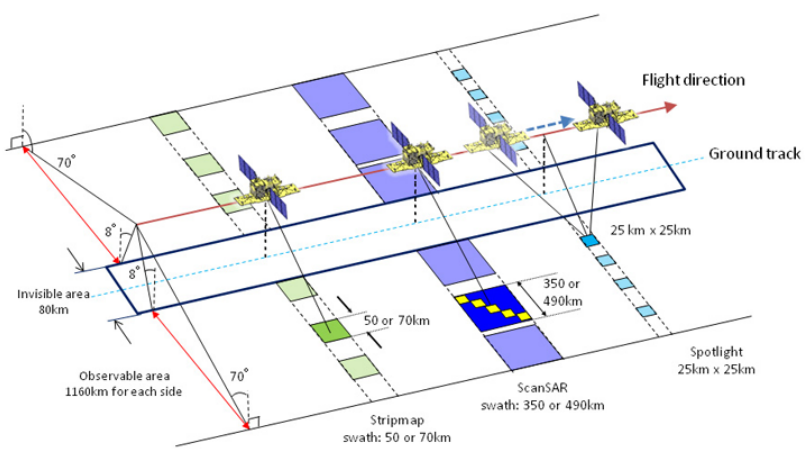

Figure 3. ALOS-2 / PALSAR-2 observation modes ${ }^{(c)}$ JAXA Copyright 1997 (JAXA, 2014)

\subsection{Corregistration}

The first step is the SAR Image Corregistration, which consists in making pixels of the same relative position in the two SAR images correspond to the same resolution cell on the ground, 


\begin{tabular}{|c|c|c|c|c|c|c|c|c|c|c|}
\hline \multirow{2}{*}{\multicolumn{2}{|c|}{$\begin{array}{l}\text { Observation } \\
\text { mode }\end{array}$}} & \multirow[b]{2}{*}{ Spotlight } & \multicolumn{5}{|c|}{ Stripmap } & \multicolumn{3}{|c|}{ ScanSAR } \\
\hline & & & \multirow{2}{*}{$\begin{array}{c}\begin{array}{c}\text { Ultrafine } \\
\text { [3m] }\end{array} \\
84\end{array}$} & \multirow{2}{*}{\multicolumn{2}{|c|}{$\begin{array}{l}\text { High sensitive } \\
\qquad \begin{array}{c}\text { [6m] } \\
42\end{array}\end{array}$}} & \multicolumn{2}{|c|}{$\begin{array}{l}\text { Fine } \\
{[10 \mathrm{~m}]}\end{array}$} & \multicolumn{2}{|c|}{ Normal } & \multirow{2}{*}{$\begin{array}{c}\text { Wide } \\
14\end{array}$} \\
\hline \multicolumn{2}{|c|}{$\begin{array}{l}\text { Bandwidth } \\
\text { (MHz) }\end{array}$} & 84 & & & & 28 & & 14 & 28 & \\
\hline \multicolumn{2}{|c|}{$\begin{array}{l}\text { Resolution } \\
\text { (m) }\end{array}$} & $\begin{array}{c}3 \times 1 \\
(\operatorname{Rg} \times A z)\end{array}$ & 3 & \multicolumn{2}{|l|}{6} & \multicolumn{2}{|l|}{10} & \multicolumn{2}{|c|}{$\begin{array}{c}100 \\
\text { (3 looks) }\end{array}$} & 60 \\
\hline \multicolumn{2}{|c|}{$\begin{array}{l}\text { Incidence angle } \\
\text { (deg.) }\end{array}$} & $8-70$ & $8-70$ & $8-70$ & $20-40$ & $8-70$ & 23.7 & \multicolumn{2}{|c|}{$8-70$} & $8-70$ \\
\hline \multicolumn{2}{|c|}{$\begin{array}{l}\text { Swath } \\
(\mathbf{k m})\end{array}$} & $\begin{array}{c}25 \times 25 \\
(\mathrm{Rg} \times \mathrm{Az})\end{array}$ & 50 & 50 & 40 & 70 & 30 & \multicolumn{2}{|c|}{$\begin{array}{c}350 \\
\text { (5 scans) }\end{array}$} & $\begin{array}{c}490 \\
\text { (7 scans) }\end{array}$ \\
\hline \multicolumn{2}{|c|}{ Polarization* } & $\mathrm{SP}$ & SP/DP & SP/DP/CP & FP & SP/DP/CP & FP & \multicolumn{2}{|c|}{ SP/DP } & SP/DP \\
\hline \multicolumn{2}{|c|}{ NESZ (dB) } & -24 & -24 & -28 & -25 & -26 & -23 & -26 & -23 & -26 \\
\hline \multirow{2}{*}{$\begin{array}{l}S / A \\
\text { (dB) }\end{array}$} & $\mathbf{R g}$ & 25 & 25 & 23 & 23 & 25 & 20 & 25 & 25 & 20 \\
\hline & $\mathrm{Az}$ & 20 & 25 & 20 & 20 & \multicolumn{2}{|l|}{23} & \multicolumn{2}{|c|}{20} & 20 \\
\hline
\end{tabular}

* SP: $\mathrm{HH}$ or HV or VV, DP: HH+HV or VV+VH, FP: HH+HV+VH+VV, CP: compact pol. (experimental)

Table 1. ALOS-2 / PALSAR-2 specifications ` JAXA Copyright 1997 (JAXA, 2014)

with the greatest possible precision (Zhu et al., 2016). Taking one of the images as a reference (Master), the result of this process is the other image (Slave) displaced on the two axes, at sub-pixel level, coinciding with each other (Figure 4).

\subsection{Interferometric Phase Generation}

After the corregistration of the complex images, the interferometric image is generated by the multiplication of the complex pixels of the first image, with the corresponding complex pixels of the second image. The phase of each pixel of the resulting image corresponds to the phase difference of the respective pixels of the two images, and this is called the Interferometric Phase or Interferogram (Jiang et al., 2019). Figure 5 shows the Interferogram generated from the corregistered images of the Figure 4.

\subsection{Interferogram Filtering}

Noise from geometric and temporal decorrelation, volume scattering and processing errors can corrupt the Interferometric Phase. In this way, the Interferogram Filtering process is carried out, which consists of the application of a noise reduction filter in order to increase the accuracy of the Interferometric Phase and consequently the Digital Elevation Model. We used the Goldstein Filter (Wang et al., 2018).

\subsection{Phase Unwrapping}

As the Interferogram has a cyclic character and in order to be used to obtain information on the height of the terrain, this cyclical character must be removed, that is, it was necessary to transform the relative phase, which has a $2 \pi$ module, into an absolute phase. This process is called Phase Unwrapping (Yu, Lan, 2016). The resulting image of this stage is precisely the Interferogram with the Unwrapped Phase, that is, without the cyclic fringes (Figure 6).

\subsection{DEM Generation}

The conversion of the absolute phase into a measure of elevation of the terrain was carried out on each of the lines of the absolute phase matrix and the method used for such transformation consists of integrating the incidence angle throughout the imaged range, in $N$ steps, corresponding to the number of points of a line of the absolute phase matrix (Tao et al., 2019).

With the absolute phase and the incidence angle of the $N$-th point and, knowing the position of the two antennas, the elevation of the $N$-th point can be calculated. Figure 7 presents the DEM (Digital Elevation Model) generated from the Interferogram of the Figure 6.

\section{RESULTS}

We used the ALOS-2 / PALSAR-2 images of the Figure 8 and we performed all the steps of the flowchart of the Figure 2: Corregistration, Interferometric Phase Generation, Interferogram Filtering, Phase Unwrapping and DEM Generation. The results were, respectively, the images of the Figure 9, Figure 10, Figure 11 and Figure 12.

After the generation of the DEM, we observed a systematic error that generated a kind of very sharp ramp in the azimuthal direction (direction of displacement of the platform), with a variation greater than 3 thousand meters in height in just $10 \mathrm{~km}$ in length. Figure 13 shows the histogram and the color scale of the DEM of the Figure 7.

This behavior (azimuth ramp) is typical of a non-constant baseline. The baseline is the distance between the two sensor crossing lines, that is, it is the difference in satellite positioning between the two acquisitions (temporally spaced).

To prove this variation in the difference, with the information from the images metadata, we plotted the positioning of the satellite in each one of the acquisitions (Figure 14).

From Figure 15, it is possible to observe that the satellite paths on the two dates undergo a relative displacement, since the centers of the blue and red dots move with each other. 


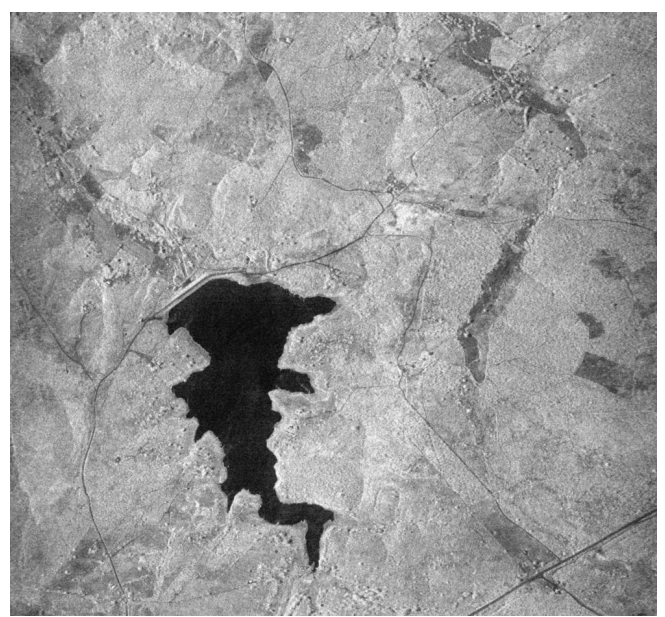

(a)

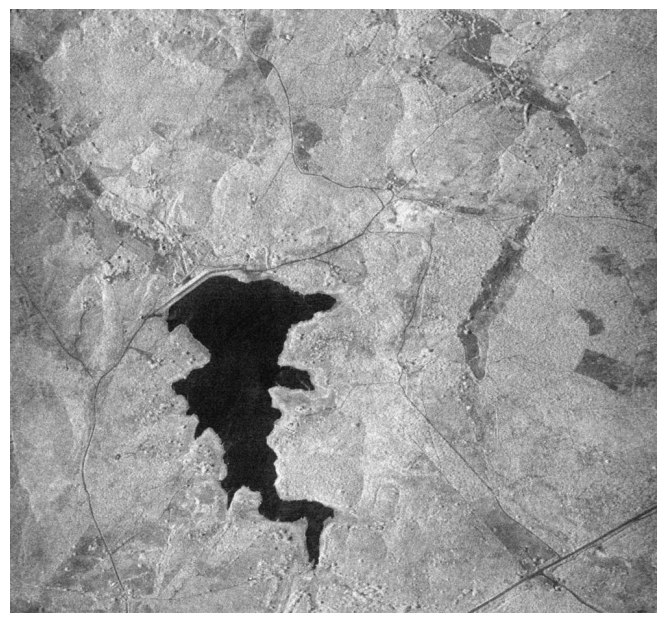

(b)

Figure 4. Example of a pair of corregistered images - Master (a) and Slave (b)

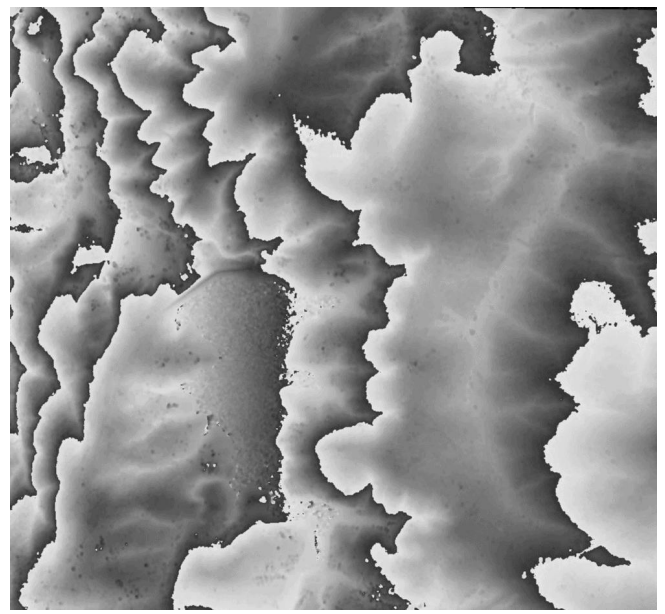

Figure 5. Interferogram generated from the corregistered images of the Figure 4

This is even more evident in the plot in Figure 16, which shows the relative distance between these two trajectories. The axes have the time in days in the first acquisition (X axis) and the time also in days in the second acquisition ( $\mathrm{Y}$ axis), with zero representing the moment of the first acquisition in the area of

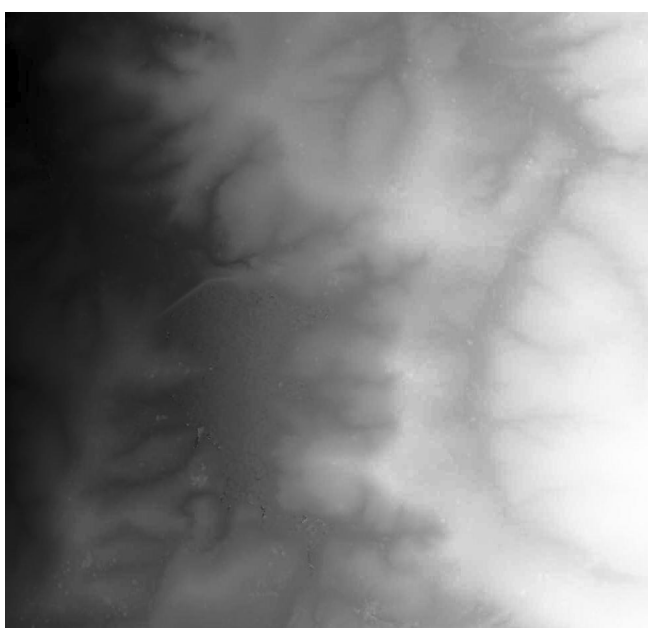

Figure 6. Interferogram with the Unwrapped Phase

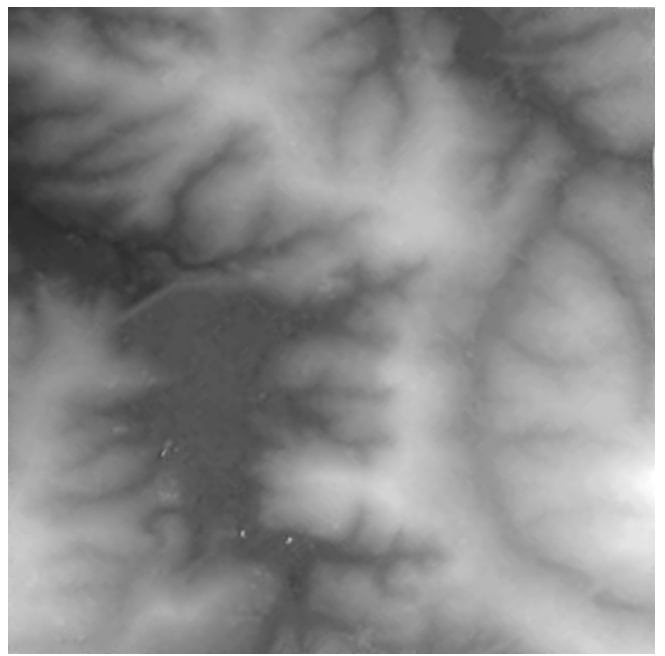

Figure 7. DEM generated from the Interferogram of the Figure 6

interest. The color scale values are in meters.

We can see that the two acquisitions are in the same position in a time interval of 14 days, exactly the revisit period of the ALOS-2 satellite.

\section{CONCLUSIONS}

In this work, we tried to generate a Digital Elevation Models (DEMs) by InSAR processing from data pairs of the ALOS-2 PALSAR-2 Ultrafine mode ( $3 \mathrm{~m}$ resolution) from two satellite passages. The images are from two forest regions in the Paraná state, Brazil. We detected a very sharp ramp in the azimuthal direction because of a relative displacement between the satellite paths on the two dates causing a non-constant baseline.

In order for correcting this effect we propose the removal of this ramp or the execution of interferometric processing taking into account the variable baseline. However, it would be necessary to use new software and carry out new research.

There are other works that propose and execute very similar methodologies. However, they either use the pair formed by the TerraSAR-X / TanDEM-X satellites, which are two satellites 


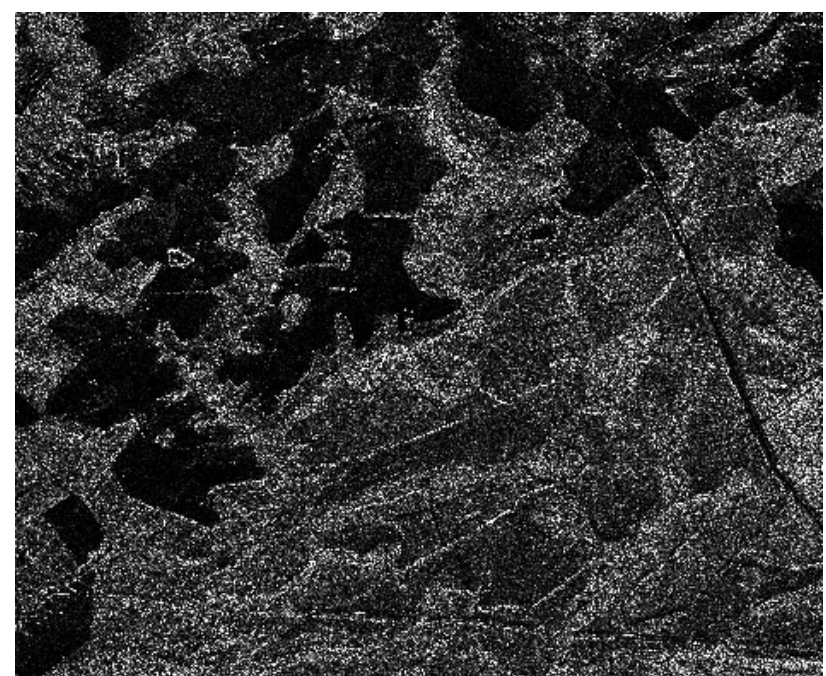

(a)

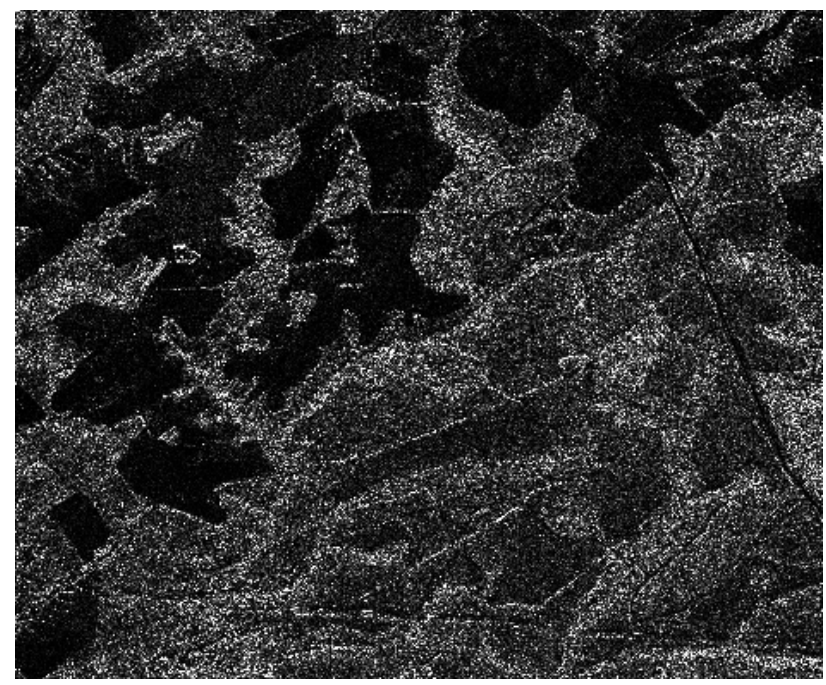

(b)

Figure 8. Pair of corregistered images - Master (a) and Slave (b)

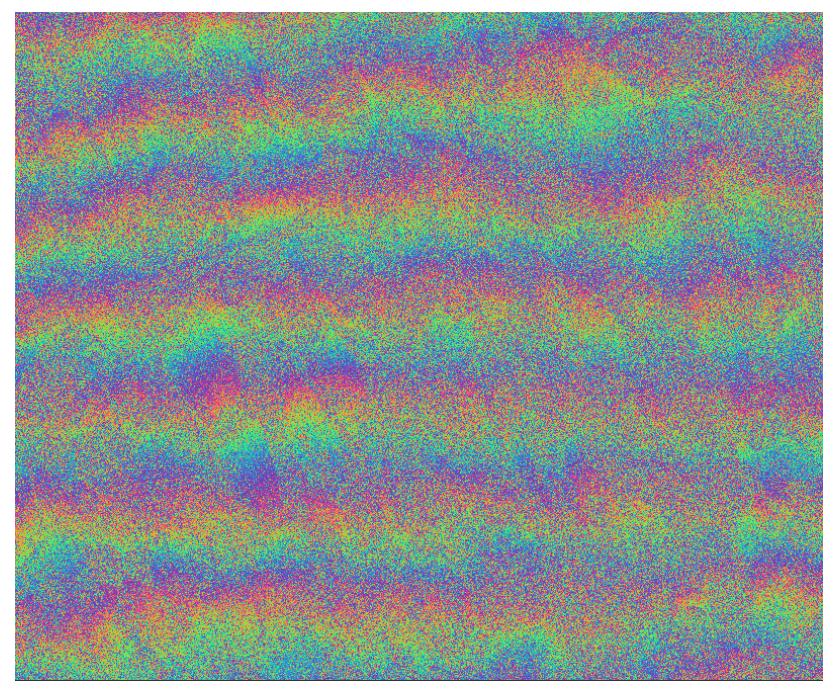

Figure 9. Interferogram generated from the corregistered images of the Figure 8

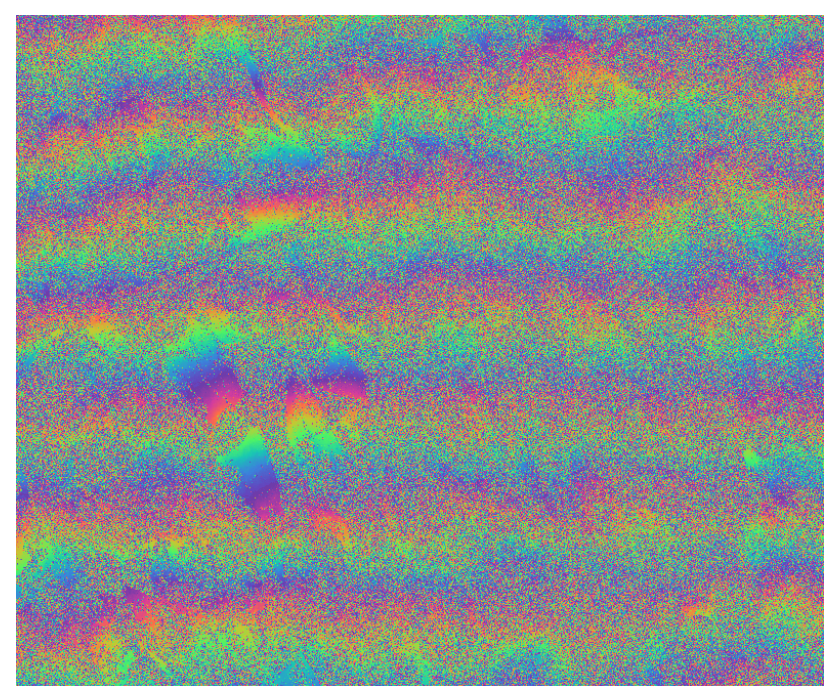

Figure 10. Interferogram of the Figure 5 after applying the Goldstein Filter

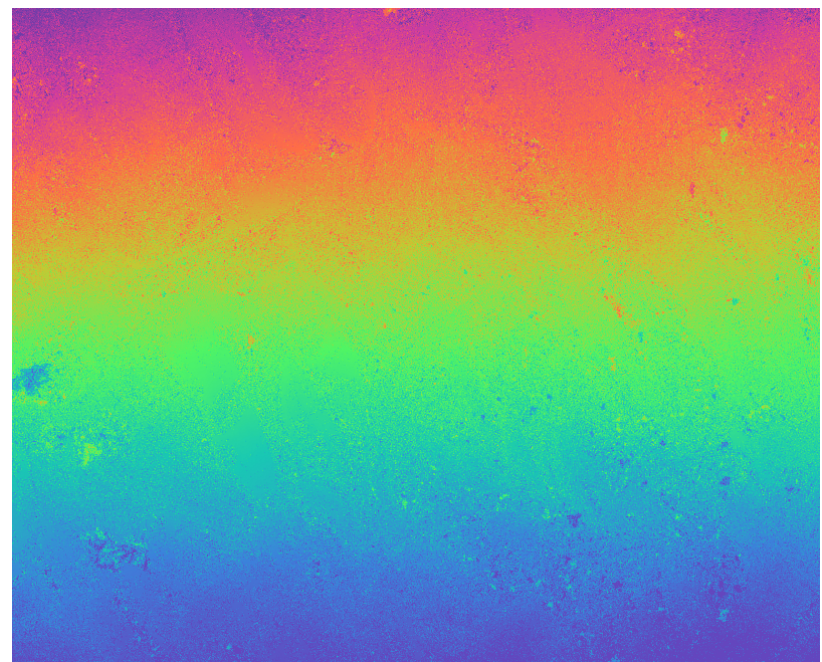

Figure 11. Interferogram of the Figure 10 with the Unwrapped Phase

that have the same orbit, one followed by the other with a constant baseline (Ali et al., 2019), or they use data from ALOS-2 / PALSAR-2 ScanSAR mode, that is, they use data with much lower resolution (from 60 to $100 \mathrm{~m}$ ) which, therefore, are much less sensitive to changes in the baseline (Natsuaki et al., 2016) (Liang, Fielding, 2017).

\section{ACKNOWLEDGEMENTS}

We would like to thank FAPESP (São Paulo State Research Support Foundation). This work was part of the R\&D project of FAPESP entitled "Geração de inventários florestais a partir de um portfólio de soluções de sensoriamento remoto brasileiras de papel e celulose" (Generation of forest inventories from a portfolio of Brazilian remote sensing solutions for paper and cellulose) number "2017 / 25639- 5 - NRC - PIPE - Fase 2 Direta”. 


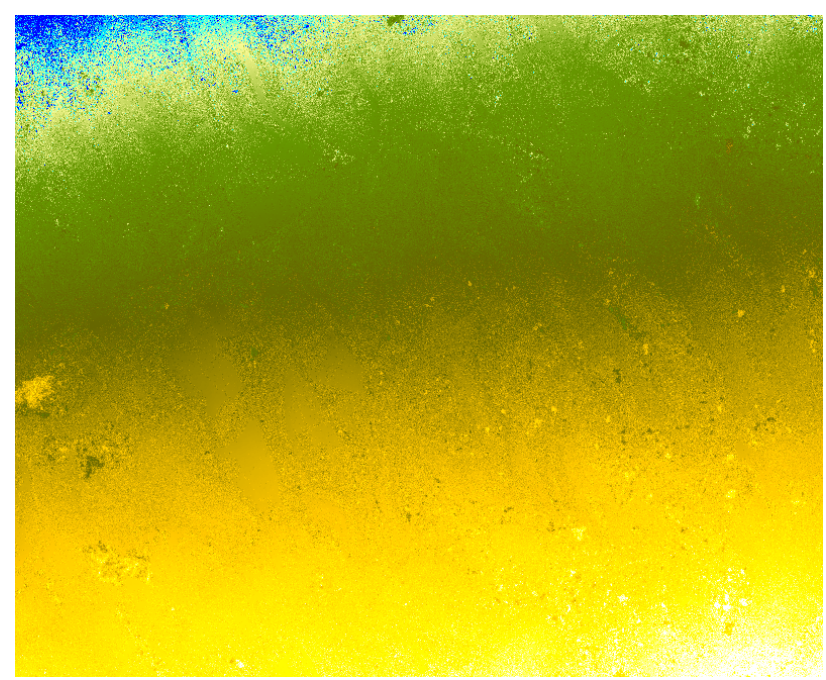

Figure 12. DEM generated from the Interferogram of the Figure 11

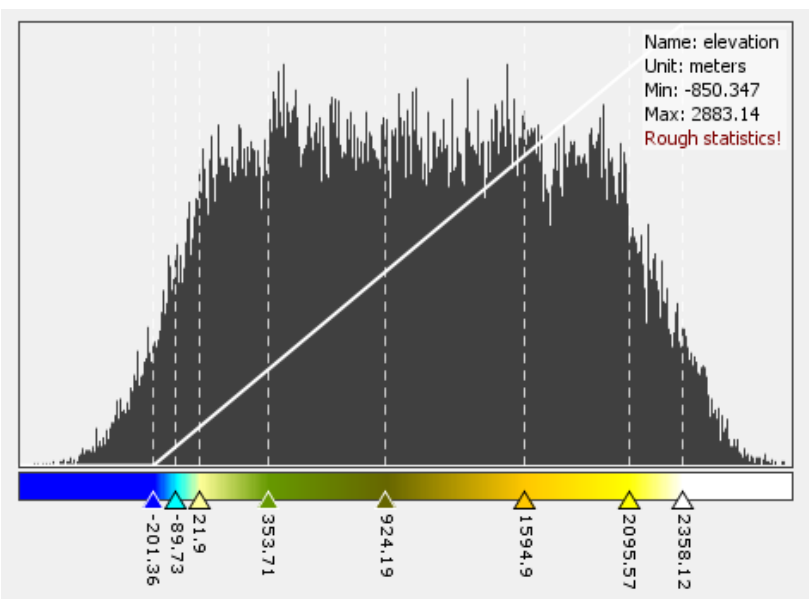

Figure 13. Histogram and Color Scale of the data of the Figure 7

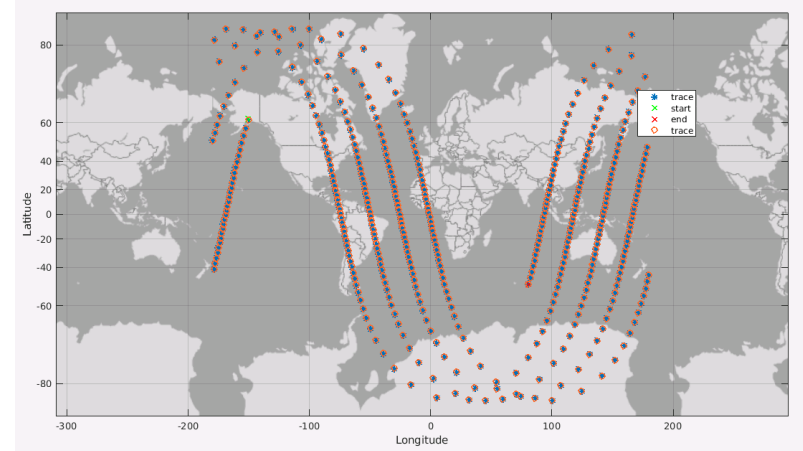

Figure 14. Positioning of the ALOS-2 satellite on both acquisition dates (blue and red)

\section{REFERENCES}

Ali, S., Arief, R., Dyatmika, H., Maulana, R., Rahayu, M., Sondita, A., Setiyoko, A., Maryanto, A., Budiono, M., Sudiana, D., 2019. Digital elevation model (dem) generation with repeat pass interferometry method using terrasar-x/tandem-x (study case in bandung area). IOP Conference Series: Earth and En-

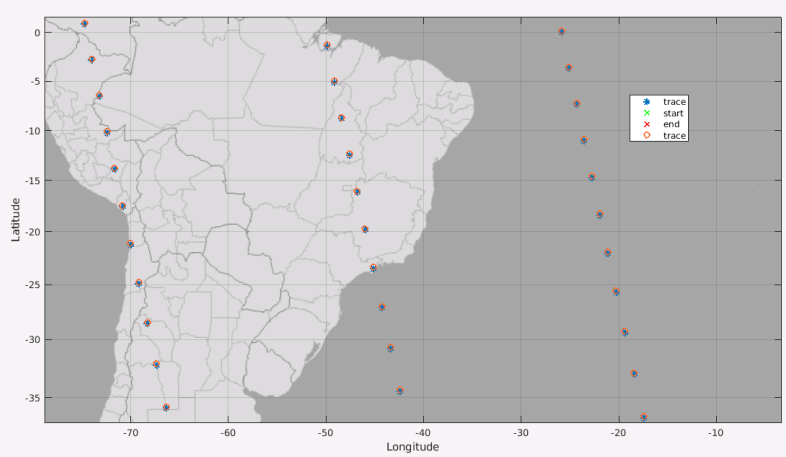

Figure 15. Zoom on Figure 14 showing the positioning of the ALOS-2 satellite during data acquisition in the area of interest

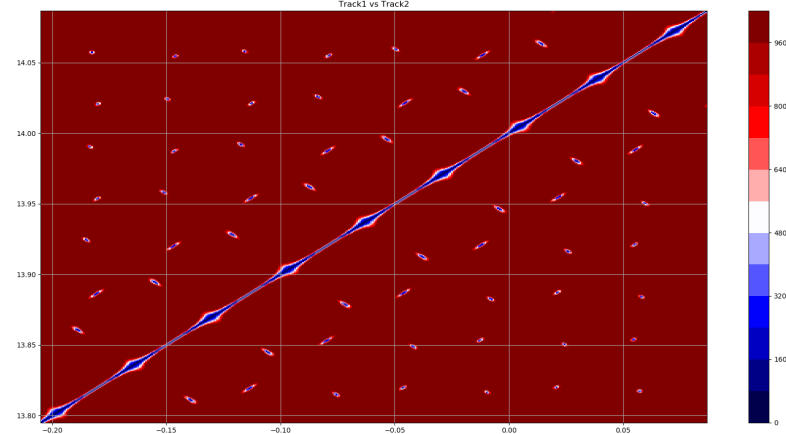

Figure 16. Plot of the positions of the ALOS-2 satellite in the first acquisition versus the second acquisition

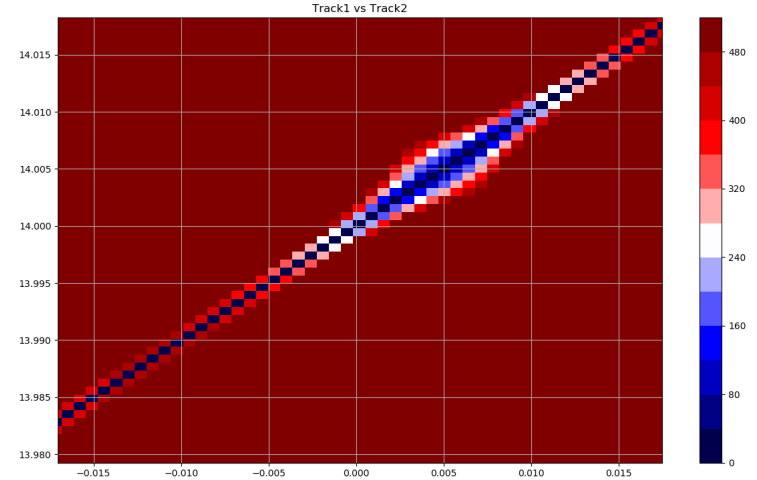

Figure 17. Zoom on Figure 16 showing the positioning of the ALOS-2 satellite during data acquisition in the area of interest

vironmental Science, 280number 1, IOP Publishing, 012019.

JAXA, 2014. ALOS-2 Project / PALSAR-2. Japan Aerospace Exploration Agency - Earth Observation Research Center. https://www.eorc.jaxa.jp/ALOS-2/en/about/palsar2.htm.

Jiang, Y., Li, J., Sun, B., Li, R., He, Z., 2019. Wrapped interferometric phase registration based positioning method. IGARSS 2019-2019 IEEE International Geoscience and Remote Sensing Symposium, IEEE, 381-384.

Liang, C., Fielding, E. J., 2017. Interferometry with ALOS-2 full-aperture ScanSAR data. IEEE Transactions on Geoscience and Remote Sensing, 55(5), 2739-2750. 
Managhebi, T., Maghsoudi, Y., Valadan Zoej, M. J., 2018. FourStage Inversion Algorithm for Forest Height Estimation Using Repeat Pass Polarimetric SAR Interferometry Data. Remote Sensing, 10(8), 1174.

Mura, J. C., Pinheiro, M., Rosa, R., Moreira, J. R., 2012. A phase-offset estimation method for InSAR DEM generation based on phase-offset functions. Remote Sensing, 4(3), 745761 .

Natsuaki, R., Nagai, H., Motohka, T., Ohki, M., Watanabe, M., Thapa, R. B., Tadono, T., Shimada, M., Suzuki, S., 2016. SAR interferometry using ALOS-2 PALSAR-2 data for the Mw 7.8 Gorkha, Nepal earthquake. Earth, Planets and Space, 68(1), 15.

Rosa, R., 2017. Minicurso: Introdução ao Sensoriamento Remoto por Radar - GEGEP/UFPE. http://rgdoi.net/10.13140/RG.2.2.33323.95521.

Tao, L., Zhong, X., Wu, T., Zhang, J., Shen, M., Qu, S., 2019. Dem generation with high-resolution repeat-pass interferometry for airborne squinted sar acquisitions. 2019 6th Asia-Pacific Conference on Synthetic Aperture Radar (APSAR), IEEE, $1-5$.

Uemoto, J., Nadai, A., Kojima, S., Kobayashi, T., Umehara, T., Matsuoka, T., Uratsuka, S., Satake, M., 2018. Extraction and height estimation of artificial vertical structures based on the wrapped interferometric phase difference within their layovers. ISPRS Journal of Photogrammetry and Remote Sensing, 139, 14-29.

Veci, L., 2015. Interferometry Tutorial. Array Systems. Available online: http://sentinell. s3. amazonaws. com/docs/S1TBX\% 20Stripmap\% 20Interferometry\% 20with\% 20Sentinel-1\% 20Tutorial. pdf (accessed on 12 August 2017).

Wang, B.-H., Zhao, C.-Y., Liu, Y.-Y., 2018. An improved SAR interferogram denoising method based on principal component analysis and the Goldstein filter. Remote Sensing Letters, 9(1), 81-90.

Yu, H., Lan, Y., 2016. Robust two-dimensional phase unwrapping for multibaseline SAR interferograms: A two-stage programming approach. IEEE transactions on geoscience and remote sensing, 54(9), 5217-5225.

Yunjun, Z., Fattahi, H., Amelung, F., 2019. Small baseline InSAR time series analysis: Unwrapping error correction and noise reduction. Computers \& Geosciences, 104331.

Zhu, H., Ma, W., Hou, B., Jiao, L., 2016. SAR image registration based on multifeature detection and arborescence network matching. IEEE Geoscience and Remote Sensing Letters, 13(5), 706-710.

Zhu, X. X., Wang, Y., Montazeri, S., Ge, N., 2018. A review of ten-year advances of multi-baseline SAR interferometry using TerraSAR-X data. Remote Sensing, 10(9), 1374. 